\title{
Bacteriophage: A Model System for Active Learning
}

\author{
CARL S. LUCIANO, ${ }^{*}$ MATTHEW W. YOUNG,${ }^{1}$ ANDROBIN R. PATTERSON ${ }^{2}$ \\ Department of Biology, Indiana University of Pennsylvania, Indiana, Pennsylvania 15705, ${ }^{1}$ and Butler \\ County Community College, Butler, Pennsylvania 16001²
}

\begin{abstract}
Although bacteriophage provided a useful model system for the development of molecular biology, its simplicity, accessibility, and familiarity have not been fully exploited in the classroom. We describe a student-centered laboratory course in which student teams selected phage from sewage samples and characterized the phage in a semesterlong project that modeled real-life scientific research. The course used an instructional approach that included active learning, collaboration, and learning by inquiry. Cooperative student teams had primary responsibility for organizing the content of the course, writing to learn using a journal article format, involving the entire group in shared laboratory responsibilities, and applying knowledge to the choice of new experiments. The results of student evaluations indicated a high level of satisfaction with the course. Our positive experience with this course suggests that phage provides an attractive model system for an active-learning classroom.
\end{abstract}

The growth of molecular biology in the 1940s and 1950s was due in part to the availability and popularity of bacteriophage as a model system. Scientists of the era regarded phage as the "atom" of biology, the simplest possible biological tool for asking fundamental questions about gene structure, gene replication, and gene expression $(4,9)$. The simplicity of phage systems would seem to make them attractive as teaching tools and indeed exercises that direct students to isolate phage can be found in several laboratory manuals $(5,11)$. However, we are aware of few published exercises involving phage that use an active-learning approach (13, K. Pidcock, Abstr. 96th Gen. Meet. Am. Soc. Microbiol. 1996, abstr. W-15, p. 477, 1996; E. Rybicki, University of Cape Town, personal communication). We sought to exploit the advantages of phage as an entry-level model system in a student-centered laboratory course that we describe in this report. The course is an inquiry-based laboratory course that highlights the role of cooperative student teams $(12,20)$ in an active-learning environment.

Instruction in the Department of Biology at Indiana University of Pennsylvania (IUP) emphasizes hands-on, experiential learning. Biology students at IUP have numerous opportunities to gain practical experience doing science, including summer internships, independent study projects, participation in faculty research, and a variety of formal laboratory courses with a distinct focus on inquiry. The bacteriophage investigation lab complements the department's active learning philosophy. It has been offered three times as a one-semester module for the course "Advanced Techniques in Biology." This course features different topics and instructors rotating through on an irregular basis, dependent on student demand and faculty interest.

The overall instructional strategy for this course had three facets. First, learning was active. Eisen and Bonwell (8) describe active learning as learning in which students are in-

*Corresponding author. Mailing address: Department of Biology, Indiana University of Pennsylvania, Indiana PA, 15705. Phone: (724) 357-2427. E-mail: luciano@iup.edu. volved in doing things and thinking about the things they are doing. The thinking is higher order, involving analysis, synthesis, and evaluation. Instructors promote this type of thinking by placing greater emphasis on development of student skills such as reading, discussing, and writing and by encouraging student exploration of their own attitudes and values $(15,16)$.

Secondly, we used teaching strategies that promoted collaboration. Whether termed group work, collaborative learning, or cooperative learning, properly structured collaboration provides an effective way to implement an atmosphere of active learning in the classroom (12). The cooperative approach has a fundamental commitment to students learning from each other and with each other rather than from the instructor.

The third facet of the instructional approach was the use of inquiry-based techniques. The structure of the phage course emphasized the process of making observations and then analyzing them in order to provide an explanation leading to a conclusion or another question. The inquiry-based strategy used in this course, probably more than the other two facets of the instructional approach, modeled "science as a way of knowing" to the students.

Within the context of our overall instructional strategy we wanted to achieve student learning in four general categories, consistent with the Biological Sciences Curriculum Study (3), a nonprofit science education organization with a 42-year history in high school biology curriculum development and teacher professional development. The four categories around which learning was organized are described in Table 1 (adapted from Reference 3).

\section{METHODS}

Course structure. We limited enrollment in the phage course in order to maximize student-faculty interaction and to allow effective monitoring of student progress. The course enrolled 11 students in 1996, 7 in 1998, and 11 in 2001. The first time the course was offered it was organized with three 
TABLE 1. Learning categories in the phage course

\begin{tabular}{lc}
\hline Learning category & Purpose \\
\hline Organizing content & $\begin{array}{c}\text { Students learn the language and content of biology and see relationships, similarities, } \\
\text { and differences }\end{array}$ \\
Writing to learn & $\begin{array}{c}\text { Students are given low risk opportunities to practice using the language of biology } \\
\text { Students are challenged to express ideas to each other, to examine, refine, modify, } \\
\text { and expand their own and others' ideas }\end{array}$ \\
Application & $\begin{array}{c}\text { Students apply what they know to a variety of multidimensional, often self-directed, } \\
\text { questions }\end{array}$ \\
\hline
\end{tabular}

teams of three students each and a fourth team of only two students. This distribution resulted in an unfair workload for students in the smaller team. Thus, in the 1998 and 2001 classes only three- and four-member teams were organized. Regularly scheduled classes met biweekly for three hours each time, but most laboratory activities took place outside regular class hours.

In each of the three classes, students were assigned heterogeneously to cooperative groups based upon demographics (including gender, major, and nationality) and self reports on academic background, laboratory experience, and other potentially useful skills such as computer expertise. In general, students who enrolled in the course had a fairly strong background in ecology and zoology but much more limited experience with microbiology, molecular biology, and associated laboratory methods. To provide a base level of background content material in these areas, we delivered traditional lectures during the first few class meetings. These lectures covered introductory aspects of phage biology and biochemistry, phage terminology, calculations (e.g., dilutions, titration, and Poisson distribution), and the phage replication cycle. We also spent time in a review of routine laboratory techniques and laboratory safety.

The course entered inquiry mode when students began content organization. Students were directed to collect sewage samples, screen them for phage, and estimate the total number of phage particles in the samples by plaque count, but they were not given a prescribed set of instructions for these clearly defined goals. Instead, student groups were charged with identifying the methods and procedures most likely to be productive by surveying and discussing the literature available to us. Our collection included lab manuals and textbook chapters $(1,2,6,11,16,20)$ as well as journal articles from instructors' collections and personal communications. When students began content organization few of them had experience handling phage, but each of them had an opinion about the subject, usually strongly held. Consequently, our approach resulted in a series of animated class discussions and required occasional instructor intervention to clear up ambiguities or resolve problems. These discussions consumed substantial class time but effectively modeled the way scientists must deal with a complex body of literature at the outset of a project. More importantly, our approach to content organization established an active, dynamic classroom atmosphere that persisted for the balance of the semester.

When the students reached consensus on the initial isolation procedures to be used, the class traveled to the local sewage treatment facility to obtain water samples. Upon our return to the laboratory, these samples were first processed by low-speed centrifugation to remove cellular and particulate material and then subjected to ultrafiltration. The ultrafiltrate was then used as inoculum for phage growth experiments. We handled all materials as biohazards, with the instructors directly monitoring all experiments to enforce strict adherence to all safety regulations. To increase the probability of obtaining different types of phage and to reduce the probability of cross contamination, each of the teams used a different host species (Enterobacter aerogenes, Escherichia coli, or Salmonella typhimurium) or different strains of $E$. coli. For phage growth under noncompetitive conditions, teams plated the clarified, filtered sewage directly in soft agar overlays along with appropriate host cells. For competitive growth, they first enriched the filtrate overnight in a broth culture of the bacterial host prior to plating in soft agar overlays on the second day. In comparisons of phage growth under competitive and noncompetitive conditions, students were surprised at the decrease in phage diversity (based on plaque morphologies) following competitive growth and were impressed with their estimate of the total number of phage particles travelling through the treatment facility each day.

The experience the students gained in the initial set of closely supervised experiments provided them with enough confidence to proceed more independently through the second set. Students selected a single plaque whose morphology was interesting to them, picked phage from the plaque using a sterile toothpick, and then amplified and determined the titer of the selected phage. The titer of the phage stocks were then used to conduct a host range experiment in which the titer of each phage on several hosts was determined (Table 2 ). In the absence of biochemical or ultrastructural data, the results of the host range experiment suggested that each group had, in fact, succeeded in isolating a different phage.

Each team then used its plaque-purified titer of phage stock to generate a one-step growth curve. In pilot experiments they first constructed a growth curve for each of the bacterial 
TABLE 2. Host range experiment

\begin{tabular}{|c|c|c|c|}
\hline \multirow[t]{2}{*}{ Hosttested } & \multicolumn{3}{|c|}{ Titer $(\mathrm{PFU} / \mathrm{ml})^{a}$} \\
\hline & Phage $\mathrm{I}^{b}$ & Phage II ${ }^{c}$ & Phage III $^{d}$ \\
\hline Enterobacter aerogenes $^{e}$ & 0 & 0 & $6 \times 10^{5}$ \\
\hline Salmonellatyphimurium ${ }^{e}$ & 0 & 0 & 0 \\
\hline Escherichia coli $\mathrm{B}^{e}$ & $1.8 \times 10^{8}$ & $3.5 \times 10^{5}$ & 0 \\
\hline E. $\operatorname{coli} C^{e}$ & $2.5 \times 10^{7}$ & 0 & 0 \\
\hline E. coli $\mathrm{K} 12^{f}$ & $1.2 \times 10^{7}$ & $2.4 \times 10^{4}$ & 0 \\
\hline E. coli $(\text { local isolate })^{g}$ & 0 & 0 & 0 \\
\hline
\end{tabular}

${ }^{a}$ Determined by plating with host cells in soft nutrient agar overlays and overnight incubation at $37^{\circ} \mathrm{C}$.

${ }^{b}$ Selected on E. coli C.

${ }^{c}$ Selected on E. coli B.

${ }^{d}$ Selected on E. aerogenes.

${ }^{e}$ Carolina Biological Supply Co.

${ }^{f}$ Ward's Natural Science Establishment.

${ }^{g}$ Provided by Allan T. Andrew.

hosts and also determined the most rapid and effective way to separate unadsorbed phage from host cells.

Assessment and accountability. To address the writing to learn component, students prepared several written assignments during the semester. Students submitted "short reports" describing the methodology and the results of individual experiments. These were cooperative assignments, with each team dividing labor and responsibility among its members. In addition to the regular review by the class instructor, who assigned the grade, short reports were critiqued anonymously by other faculty members in the Biology department. Students were required to respond to the comments of the anonymous reviewers and, in most cases, to revise the short reports and resubmit them. At the end of the semester, each student prepared a comprehensive report of the group's research, written in the format of an article published in a virology journal such as Virology, Journal of Virology, or Journal of General Virology. The comprehensive reports were reviewed by the course instructor, who assigned an individual grade for each student, but they were not reviewed by anonymous reviewers. The manner in which grades were divided between short reports (group grades) and the comprehensive report (individual grade) provided both the group incentives and the individual accountability required for successful cooperative learning (18).

As an additional way to ensure individual accountability, student learning was assessed using a midsemester examination and a final examination, both of which consisted entirely of essay questions. Exam questions were designed to assess higher-order learning and comprehension. Synthesis questions tested students' ability to recognize and discuss related information from several assigned readings or to draw parallels with unfamiliar information. Practical questions tested students' understanding of the appropriate use of reagents, instruments, or other laboratory materials and techniques. Analytical questions tested students' ability to critique experiments, design new experiments, or interpret re- sults. Underscoring the importance placed on written communications skills in this course, most of each student's grade was based on the quality of written product. Because the production of group data affected the quality of the comprehensive report, it is difficult to estimate the final grade breakdown between its individual and group work components. Individual performance accounted for approximately $60 \%$ of the formal course grade and group performance accounted for approximately $40 \%$.

To make sure that all students participated fully in the activities of their group, instructors met regularly with each student team. Some of these meetings took place during regularly scheduled classes and some took place outside class hours. When meetings were used to select and plan new experiments, the instructor acted in the role of a facilitator or a resource person providing task assistance. When meetings were used to review previous experiments the instructor acted in the more traditional role of critic and evaluator. Private conferences with individual students were used to discuss personality problems or issues relating to students who did not accept a fair share of the group's responsibility.

We used inquiry as the most important part of the application component of the phage course. In this component, students were charged to use the information they had learned about their phage to generate new questions and design suitable experiments to address those questions. Students understood that each team would chart its own course, but they also understood that the quality of their written reports, and hence their final grade, was dependent on productivity.

Following completion of the one-step growth curve experiment, student teams designed all subsequent experiments in response to questions they had generated. Because students in the course were invariably interested in genetic technology, all of the teams chose to focus on purification of sufficient phage for subsequent biochemical analysis rather than to investigate biological or genetic properties of phage. With a level of success that varied substantially from group to 
group, phage particles were concentrated from plate lysates by polyethylene glycol precipitation followed by ultracentrifugation in cesium chloride density gradients or through sucrose cushions. In either case, phage preparations were deproteinized by phenol extraction or commercial spin column kits. The resulting nucleic acid fraction was analyzed by agarose gel electrophoresis and restriction enzyme fingerprinting. Phage proteins were analyzed by sodium dodecyl sulfate-polyacrylamide gel electrophoresis and methylene blue staining.

\section{RESULTS}

Course evaluation by students. Students were asked to submit a formal end-of-course critique using a universitywide evaluation instrument. Response was voluntary but 25 of the 29 students who enrolled in the course elected to complete this evaluation. Combined responses from all three classes appear in Table 3 and indicate a highly favorable student attitude toward the course and its method of delivery. Even though the phage course required a significant out-ofclass time commitment, all 25 respondents said they would recommend the course to a friend. Interestingly, there was no indication that students perceived our decision to use a heterogeneous collection of readings in the course instead of a regular laboratory manual as a negative factor. In spite of its unstructured approach when compared to traditional courses, the majority of students felt that the phage course was logical, its objectives were clear, and its major points established. All 25 students thought the course stimulated critical thinking and that they had learned something valuable.

Students were asked to identify the most valuable feature of the course in a separate section of the evaluation. Of the 18 students who chose to provide an answer to this openended question, 10 identified practical laboratory experience in some form as the most valuable feature of the course. Four students listed "independence" as the response to this ques- tion and three others answered "teamwork" or "group skills." Only one student thought that the information on phage biology and genetics was the most valuable feature of the course. Of the nine students who chose to identify a second most valuable feature, three identified "laboratory skills," three "problem-solving skills," two "teamwork," and one "phage information."

Evaluation instruments encouraged students to provide unstructured written comments on any and all features of the phage course. Their responses provided additional insight about their attitudes toward the course. Typical responses included the following. "Very independent, not a cookbook course, made you think. I like that." "I liked the freedom to make mistakes and learn from them." "It was no longer a cookbook science. It began to make sense." Other students used the words "fun," "unique," or "independent thinking" in their descriptions of the course.

We conducted follow-up interviews with students from the 1996 and 2001 classes but were unable to contact any students from the 1998 class. The follow-up interviews thus took place from 6 months to 5 years after students had completed the course. Retrospective student attitudes were much the same as those expressed in course evaluations, but comments were more thoughtful. "This course challenged the students to find the holes and problems in the logic, the results, and techniques and either work around them or understand the shortfalls inherent in what is being done and make a side experiment to make up for the weakness." "I learned a lot about lab experience from the ground up. We started with nothing but the sample of wastewater and just went from there. Everything we needed we had to do ourselves. Not only did we learn about lab work and technique, but we also had to learn to work as a team and function together." Two students volunteered the opinion that their experience in the phage course enabled them to gain employment as lab technicians.

Assessment of student progress. Students at IUP are accustomed to writing-intensive courses but not to the exact-

TABLE 3. Student evaluations of the phage course

\begin{tabular}{|c|c|c|c|c|c|}
\hline \multirow[b]{2}{*}{ Evaluation item $^{a}$} & \multicolumn{5}{|c|}{ Student response (\% of respondents $)^{b}$} \\
\hline & $\begin{array}{c}\text { Strongly } \\
\text { agree }\end{array}$ & Agree & Disagree & $\begin{array}{l}\text { Strongly } \\
\text { disagree }\end{array}$ & $\begin{array}{l}\text { No } \\
\text { response }\end{array}$ \\
\hline The course was organized, logical, and coherent & 44 & 48 & 8 & 0 & 0 \\
\hline The course encouraged questions and discussion & 28 & 52 & 8 & 0 & 12 \\
\hline Texts and readings were useful & 52 & 48 & 0 & 0 & 0 \\
\hline Major points were established & 52 & 40 & 4 & 0 & 4 \\
\hline Course objectives were clear & 44 & 56 & 0 & 0 & 0 \\
\hline The course workload was more than in other courses & 32 & 36 & 32 & 0 & 0 \\
\hline The course encouraged critical thinking & 76 & 24 & 0 & 0 & 0 \\
\hline I learned something valuable in this course & 76 & 24 & 0 & 0 & 0 \\
\hline I would recommend this course to a friend & 76 & 24 & 0 & 0 & 0 \\
\hline
\end{tabular}

${ }^{a}$ Taken from an official university-wide instrument.

${ }^{b}$ Voluntary responses from all three offerings of the course $(n=25)$, total enrollment was 29. 
ing standards of peer review for publication. Consequently, when they prepared the first of their short reports, students usually did not pay sufficient attention to detail, and comments from anonymous reviewers reflected this. The anonymous reviewers pointed out numerous problems and downright errors in format and presentation. These included the incorrect use of scientific terms and species' names, omission of captions or legends, and inconsistencies within a single figure or table. The most frequent comment from anonymous reviewers was that students provided insufficient detail to repeat experiments. The reviewers also pointed out more substantial writing problems that included failure to communicate a clear meaning, conclusions unjustified by available data, and other lapses in logical thinking. Of course the students were not pleased by criticisms they regarded as trivial or by the requirement to revise and resubmit their work. Nevertheless, their written products improved quickly and negative comments on subsequent short reports were few. By the time they submitted their comprehensive reports, their efforts were relatively polished and free from errors.

Because the student population of the phage course was very small, instructors were able to meet frequently with teams or individual students. These processing sessions provided an effective way to review progress, set objectives, and organize efforts. Frequent meetings with teams also allowed the instructor to directly assess changes in the group's ability to organize course content or in the level of an individual's involvement in the group. Individual conferences provided an opportunity for students to air grievances or discuss their problems involving another student who was not adequately sharing work. This issue came up once during each offering of the course, and in each case the instructor asked group members to confront the problem and resolve it within the group if possible. Peer pressure among the students was such that this approach was invariably successful.

The small size of the class also allowed instructors to assess improvement in students' application skills. Initially, students were not skillful at asking focused questions, designing appropriate tests, and organizing experiments. Class meetings were often characterized by much discussion and little action, minimizing productivity. This was compounded by the way that the teams tended at first to organize and schedule their experiments in sequence rather than in parallel. Application skills improved as students gained experience in the laboratory and accumulated content knowledge. Improvement in application skills varied from team to team but became obvious in most teams by about a quarter of the way through the semester. Planning and organizational skills typically continued to improve markedly during the course, evident as all the teams rapidly moved through several biochemical experiments at the end of the semester.

Overall, students responded very positively to the semiindependent nature of the course and to its component of group involvement. They expended many hours of effort outside regularly scheduled classroom time in order to prepare reagents and media, conduct experiments, and maintain the laboratory. At several points all the groups in the class reached a consensus about the direction of their investigations, with distinct division of labor aimed at a common goal. In the 1996 offering of the course, for example, the design of the bacterial growth curve experiments called for aroundthe-clock monitoring by relays of students working in shifts, making these experiments the most laborious and challenging of the semester. However, this set of experiments proved to be a highly productive effort because it forced the students to make decisions and operate in a fashion that was truly collaborative and also highly functional. For the 1996 class, cooperative work within and among student groups first clearly emerged with this large-scale experiment.

\section{DISCUSSION}

Although college and university faculty generally endorse the use of active learning in the classroom, most are probably unaware of the degree of activity required for real learning to occur. One measure of the degree of active learning is the extent to which all students are involved in processing content. A second measure determines how often they are involved; learning is active when opportunities for engagement occur regularly and frequently. A third measure looks at the depth to which students are involved in thinking about content (3). In the phage course, students were heavily involved in processing and organizing content as they reviewed phage literature and their own data. Students were engaged in their work several times each week as they planned or conducted experiments. Students thought about course content as they wrote the reports and the examinations that accounted for most of their grade. Thus, by the metrics described above, the phage experience effectively modeled active learning.

In our judgment the phage course has been a success, but we also encountered several problems. One was the result of the decision to begin laboratory work as soon as possible in order to accustom students quickly to the empirical, handson style of the course. Some of the students were less than comfortable with this "jump-start" approach. Disoriented, they felt that it would have been more useful to spend more class time on preliminary lectures or to include a separate lecture component with the course. A second problem involved the significant amount of class time consumed by the cooperative decision-making process, especially at the beginning of the semester. Several students commented that the loss of time early in the course seriously limited their overall productivity. A third problem stemmed from the risk-taking nature of the course, described by one of the students as "nosafety-net science" that provided no guarantee of success. For example, one team in the 1996 class was understandably frustrated when, after several attempts, they were unable to collect sufficient phage for biochemical analysis. Lacking time in the semester to pursue different methods, the instructors could only emphasize the fact that such might be the outcome of any "real-life" research project.

The small size of the phage course and the logistical difficulties associated with student, faculty, and laboratory sched- 
uling made it impossible for us to establish a control group of students that utilized phage but was not exposed to an active- and cooperative-teaching approach. Without such a control group we cannot assert that our method was more effective than alternative approaches. However, the responses and comments on student evaluations as well as the results of follow-up interviews indicate that students preferred the active-teaching approach used in the phage course to the other approaches with which they were familiar. Students commented frequently that they had experienced a different type of learning in the phage course when compared to other courses. This outcome is expected of a successful cooperative-learning experience (12).

In teaching this class we used an approach that differs from the typical pedagogical techniques associated with teaching biology. Our approach was broader and more flexible; the learning was student-centered with less reliance on a teacher as the conduit of information. This approach extends the realm of learning beyond what the student knows to what the student can do $(7,10,14,16,21)$.

We found that bacteriophage was an effective tool for a class utilizing an active-teaching approach. Student experiments with phage were rapid, straightforward, relatively inexpensive, and as open-ended as desired. Most of the experiments were technologically simple and thus accessible to students with minimal training. Moreover, phage experiments were well suited for investigations by cooperative teams because techniques were easy to standardize. Thus, the same desirable characteristics that made bacteriophage the mainstay of molecular biology in the 1950s make it an ideal tool for the active-learning classroom in the twenty-first century.

\section{ACKNOWLEDGMENTS}

We express our gratitude to Frank Baker, Barkley Butler, David Dunnigan, Fred Eiserling, Robert Hinrichsen, Linda Fisher, Tom Lord, and Terry Peard for their advice and their assistance as "anonymous reviewers." Thanks also to Robert Askew for excellent technical assistance. This project received support from the National Science Foundation (DUE \#9851581), and from the College of Natural Sciences and Mathematics, the Graduate School, and the Biology Department at IUP.

\section{REFERENCES}

1. Ackerman, H. W., and S. DuBow. 1987. Viruses of prokaryotes, vol. I: general properties of bacteriophages. CRC Press, Inc., Boca Raton, Fla.

2. Adams, M. 1959. Methods of study of bacterial viruses, p. 443-523. In R. Hotchkiss and N. Bruce (ed.), Bacteriophages. Interscience Publishers, Inc., New York, N.Y.

3. Biological Sciences Curriculum Study. 1999. Biological perspectives: a resource manual for an active, collaborative, and inquiry-based curriculum. Kendall-Hunt Publishing Co., Dubuque, Iowa.

4. Cairns, J., G. S. Stent, and J. D. Watson. 1992. Phage and the origins of molecular biology, expanded edition. Cold Spring Harbor Laboratory Press, Cold Spring Harbor, N.Y. 5. Cappucino, J., and N. Sherman. 2001. Microbiology: a laboratory manual, p. 237-242. Benjamin Cummings, San Francisco, Calif.

6. Carlson, K., and E. Miller. 1994. Working with T4, p. 421-437. In J. Karam(ed.), Molecular biology of bacteriophage T4. ASM Press, Washington, D.C.

7. Clough, M., and R. Clark. 1994. Cookbooks and constructivism: a better approach to laboratory activities. Sci. Teacher 61:34-37.

8. Eisen, J. A., and C. Bonwell. 1993. Recent works on using active learning strategies across the disciplines. ERIC Document Services ED364135.

9. Fischer, E., and C. Lipson. 1988. The atom of biology, p. 105-130. In Thinking about science: Max Delbruck and the origins of molecular biology. W. W. Norton and Co., New York, N.Y.

10. Gallagher, J. 1993. Secondary science teachers and constructivist practice, p.181-191. In K. Tobin (ed.), The practice of constructivism in science education. Lawrence Erlbaum Associates, Hillsdale, N.J.

11. Goldstein, G. 1992. Introductory experiments in virology, p. 27-33. William C. Brown Publishers, Dubuque, Iowa. 12. Johnson, D., R. Johnson, and K. Smith. 1991. Active learning: cooperation in the college classroom. Interaction Book Co., Edina, Minn.

13. Levin, R. A. 1993. Isolating multiple strains of Escherichia coli for coliphage isolation, phage-typing and mutant recovery. In C. Goldman (ed.), Tested studies for laboratory teaching, proceedings of the 15th Workshop/Conference of the Association for Biology Laboratory Education (ABLE). Association for Biology Laboratory Education, Williamsport, $\mathrm{Pa}$.

14. Linn, M., and N. Burbules. 1993. Construction of knowledge and group learning. p. 91-119. In K. Tobin (ed.), The practice of constructivism in science education. Lawrence Erlbaum Associates, Hillsdale, N.J.

15. Okebukola,P. 1986. Cooperative learning and students' attitudes to laboratory work. School Sci. Math. 86:582-590. 16. Russell, T. 1993. Learning to teach science: constructivism, reflection, and learning from experience, $\mathrm{p}$. 248-258. In K. Tobin (ed.), The practice of constructivism in science education. Lawrence Erlbaum Associates, Hillsdale, N.J.

17. Sambrook, J., E. Fritsch, and T. Maniatis. 1989. Molecular cloning: a laboratory manual, 2nd ed. Cold Spring Harbor Laboratory Press, Cold Spring Harbor, N.Y.

18. Slavin, R. 1987. Cooperative learning: student teams, 2nd ed. National Education Association, Washington, D.C. 19. Snustad, D., and D. Dean. 1970. Genetics experiments with bacterial viruses. W. H. Freeman and Co., San Francisco, Calif.

20. Watson, S. 1992. The essential elements of cooperative learning. Am. Biol. Teacher 54:84-86.

21. Yager, R. 1991. The constructivist learning model. Sci. Teacher 58:52-57. 